\title{
Experiences of Cultural Activities provided by the Employer in Finland
}

\section{Katinka Tuisku'}

Deputy Chief Psychiatrist, Department of Psychiatry, University of Helsinki and Helsinki University Central Hospital, Finland

\section{Pia Houni}

Senior researcher, Finnish Institute of Occupational Health, Finland

\begin{abstract}
The increasing mental demands of healthcare work call for developing complementary health promotion strategies. Cultural leisure activities have long been recognized as a source of wellbeing and coping for employees. Yet, little is known about implementation of employer-provided cultural activities - how they are encountered and experienced. In this study, a public sector hospital department offered monthly cultural events for personnel: Theater, concerts, musicals, dance-performances, museum visits and sight-seeing. A digital questionnaire was sent to hospital staff ( $N=769$ ) to ask about their participation in employer-provided cultural activities during the past 6 months. The motives and obstacles for participation, and the quality of experience of the cultural events, were explored quantitatively and qualitatively. The main motives for participation were related to well-being, content of cultural events and invitations from employer or colleagues. For some, the participation was hampered by work-shifts and missing information. The participants experienced recreation, relaxation and psychological detachment from strain, which is essential for recovery. Community participation was more common than individual participation. Shared cultural experiences among employees may increase the social capital at workplace, but equal access for all employees should be guaranteed.
\end{abstract}

\section{KEY WORDS}

Cultural activity / Health promotion / Hospital personnel / Well-being

\section{Introduction}

raditionally, the worksite health promotion programs have included physical exercise, but the increasing mental demands of working life call for complementary approaches. Cultural leisure activities are associated with better coping with work-related stress (Iwasaki et al., 2005) and well-being at work (Tuisku et al., 2011). Cultural activity seems to protect employees from mental exhaustion (Theorell et al., 2013). Mental well-being is increased by community-based cultural leisure activities (Jones et al., 2013) and community art programs have health-promoting effects in disadvantaged populations (Kelaher et al., 2014). Workplace art activities in the healthcare sector seem to reduce burnout (Bittman et al., 2003) and increase occupational well-being (Bygren et al., 2009).

\footnotetext{
${ }^{1}$ Helsinki University Central Hospital, 00029 HUS Finland, E-mail: katinka.tuisku@hus.fi
} 
The well-being of healthcare employees is of special concern these days due to a shortage of personnel and increased occupational demands. Due to growing positive evidence of the cultural activities, an increasing number of employers have taken an interest in them. In Finland, since 2009, employers have been able to offer their employees tax-free vouchers for cultural events. The effects of culture vouchers have not been systematically studied (Hyyppä, 2014). The cultural vouchers have become increasingly popular, but there are no exact data about the usage. According to a national news report (2013), up to one-fifth of the vouchers may be wasted and up to one-third of the employees may give them away to other consumers. About quarter of the recreation budgets of Finnish employers are allocated to vouchers for cultural and sports services (National news, 2013).

Helsinki University Central Hospital Medical Unit was among the first large-scale public sector employers in Finland to introduce cultural events organized on a regular basis and available to all employees. The aim of the study was to establish how the participants were selected, their motives for taking part and how they experienced the cultural events.

Another aim was to find out which specific benefits are subjectively obtained by participation in a cultural program. According to previous occupational wellbeing studies (Kinnunen et al., 2011) and cultural intervention studies (Bittman et al., 2003; Bygren et al., 2009), we hypothesized the following psychosocial benefits to be experienced by workplace cultural events: psychological detachment from strain, relaxation, recreations, new ideas, reflection on professional identity, familiarization with workmates, increased communication, better atmosphere and cooperation in the workplace.

\section{Materials and Methods}

Hospital personnel of the Medical Unit at Helsinki University Hospital launched an employer-provided cultural activity program during 2011, which was regular, informed and available to all personnel during 2012. The recreational cultural activity program included events such as theater, concerts, musicals, dance-performances and guided museum and sight-seeing tours. The cultural events were scheduled outside working hours and participation was voluntary. Employees were invited to cultural events by workplace website information and meeting communications. They enrolled and reserved the tickets by organization website.

A survey of the experiences of cultural activity during the past 6 months was conducted by means of an anonymous questionnaire in September 2012. The digital questionnaire was sent to all email addresses included in the personnel register (2463). The amount of active addresses (employees working at the time of enquiry) was not known, but approximately $90 \%$ of the personnel were present considering holidays, family-leave, sick-leave, education and other absences. As 769 employees responded the questionnaire, the concluded response rate was approximately $35 \%$.

The majority of respondents were female nurses in permanent employment reflecting the overall structure of personnel. The age, gender, profession, work shifts and type of employment were asked by the questionnaire, and these qualities were compared between participants and nonparticipants by Crosstabs and T-test. 
The main outcomes were explored by multiple-choice categorized questions about the frequency of participation during the past 6 months, how many work colleagues they met at the cultural event, reasons for non-participation, motives for participation, type of cultural event, quality of the experience from the cultural event and the experienced benefits of the cultural event. The quality of experience was categorized by a 5-class scale ranging from negative to positive. The subjective benefits of participation were reported by 1-5 Likert scale for nine different items according to hypothesis (Tab. 2).

For qualitative analysis, there was an open question: 'Describe your experience of the cultural event in your own words'. Furthermore, some of the multiple-choice questions included an empty choice 'other' to be completed as appropriate. The open-ended questions were intended to evoke responses that are meaningful and culturally salient to the participant and unanticipated by the researcher. The open questions were analyzed by thematic coding with discourse analyses applied here as investigation of contents in relation to context, categorized attitudes, terminology and semantic data. The leading themes and their relationships to study questions were analyzed.

Discourse analysis studies the use of discourses and how people use language to create meanings, define things around them and construct social reality. In discourse analysis, language and reality are not seen as a relational, but rather language is an active process to construct reality. Analysis of discourse takes into consideration the surrounding social and historical contexts, which is the platform for communication that exists in society. In the present study, this method was used to study responses whose theme was how arts and cultural activity support well-being at work (Gee, 2005; Willig, 2008).

The study was approved by the Ethics Committee of Finnish Organization of Occupational Health on 2 March 2012 and the study permission was granted by the leader of Helsinki University Central Hospital Medical Unit on 10 February 2012.

\section{Results}

\section{Participant characteristics}

Most of the respondents (59\%) had not yet participated in any cultural activities provided by employer. Those who participated were slightly older, predominantly females $(95 \%)$, permanently employed $(93 \%)$ and working official hours $(59 \%)$ compared with those who did not participate. The differences between participants and non-participants were significant (Tab. 1). Among the non-participants, the proportion of females was $90 \%$, of whom $85 \%$ were permanently employed and $45 \%$ were daytime workers. Most of the participants had participated once or twice and they were most often accompanied by more than two workmates (Tab. 1 ).

\section{Motives for participation}

The most important motives for participation were either related to personal well-being, such as recreation $62 \%(\mathrm{~N}=193)$ and relaxation $46 \%(\mathrm{~N}=144)$, or the attraction of the event itself, the interest to the specific form of art $41 \%(\mathrm{~N}=128)$ or general appreciation of the arts $40 \%(\mathrm{~N}=124)$. Other motives were information and invitation from 
Table I Qualities of participants and type of participation

\begin{tabular}{|c|c|c|c|c|}
\hline Comparison & Participation & No participation & $\begin{array}{l}\text { Significance } \\
\text { of difference }\end{array}$ & Test \\
\hline$N(\%)$ & $311(40.8 \%)$ & 45 I (59.2\%) & & \\
\hline Mean age & 47.4 years & 43.2 years & $p<0.0005$ & T-test \\
\hline Sex ratio F/M & $296 / 15$ & $406 / 45$ & $p=0.009$ & Chi-square \\
\hline $\begin{array}{l}\text { Work hours } \\
\text { Daytime/Shift }\end{array}$ & $183 / 125$ & $202 / 248$ & $p<0.0005$ & Chi-square \\
\hline $\begin{array}{l}\text { Work contract } \\
\text { Perm./Temp. }\end{array}$ & $290 / 19$ & $381 / 68$ & $p=0.001$ & Chi-square \\
\hline \multicolumn{5}{|l|}{ Profession } \\
\hline Nurses & $215(69 \%)$ & $313(69 \%)$ & $p=0.003$ & Chi-square \\
\hline Doctors & $9(3 \%)$ & $63(14 \%)$ & $p<0.0005$ & Chi-square \\
\hline Other & $87(28 \%)$ & $75(17 \%)$ & $p<0.0005$ & Chi-square \\
\hline Type of participation & \multicolumn{2}{|c|}{$\mathrm{N}=31$ I who participated } & \multicolumn{2}{|c|}{ Percentage of Respondents } \\
\hline \multirow[t]{5}{*}{ Frequency } & \multicolumn{2}{|c|}{ How many times } & & \\
\hline & \multicolumn{2}{|c|}{ I } & 181 & $58.2 \%$ \\
\hline & \multicolumn{2}{|c|}{2} & 79 & $25.4 \%$ \\
\hline & \multicolumn{2}{|c|}{3} & 28 & $9.0 \%$ \\
\hline & \multicolumn{2}{|c|}{$>3$} & 23 & $7.4 \%$ \\
\hline \multirow[t]{4}{*}{ Community } & \multicolumn{2}{|c|}{ How many workmates } & & \\
\hline & \multicolumn{2}{|c|}{0} & 23 & $7.6 \%$ \\
\hline & \multicolumn{2}{|c|}{$1-2$} & 126 & $41.4 \%$ \\
\hline & \multicolumn{2}{|c|}{$>2$} & 155 & $51.0 \%$ \\
\hline
\end{tabular}

the employer $24 \%$, being asked by a workmate $22 \%$ and curiosity $10 \%$. Only $3 \%$ chose item 'Other motives' and $1 \%$ chose item 'I do not know'. Several items could be chosen.

\section{Reasons for non-participation}

The respondents were asked about obstacles for participation by multiple-choice questions with an open option. Several items could be chosen. The two most outstanding reasons reported for non-participation were lack of information $33 \%(\mathrm{~N}=150)$ and lack of time $33 \%(\mathrm{~N}=148)$. They were followed by other obstacles, such as lack of interest $24 \%$, work-shift $19 \%$, family $17 \%$, lack of energy $13 \%$, priority of individual cultural activities $12 \%$, lack of company $7 \%$, forgetting $7 \%$, studies $2 \%$ and other reasons $18 \%$.

The open responses in the category 'other reasons' most often revealed difficulties in obtaining tickets for cultural events. The shift-workers reported to be in an unequal position, as all the tickets were quickly booked by day-time workers. Two major problems were 
mentioned: how to find out information about activities and how to be on the intranet at the right time to book tickets.

Personal reasons for non-participation were reported by 23 respondents. The majority of them were active outside the workplace pursuing many personal hobbies. Additionally, a few respondents mentioned travel difficulties related to long distances and some reported having been on holiday or sick-leave at the time of cultural event.

The category 'other' also included 51 positive comments about the cultural events even if the respondents did not participate themselves. The rest, 10 free responses consisted of work-related explanations for non-participation.

\section{Types of cultural events}

The most frequently visited cultural events were theater $40 \%(\mathrm{~N}=125)$ and concerts $33 \%$ (102). Next were exhibitions 24\%, movies $12 \%$ and dance 3\%. Many selected the item 'other', which mainly included, according to descriptions, museum visits, sight-seeing and music performances. It was possible to choose several different cultural events according to individual choice during the past 6 months.

\section{Quality of participation experience}

Most of the responses reported the cultural experience as either positive (76\%) or quite positive $(21 \%)$, and no responses signaled a negative experience $(0 \%)$. Two responses reported quite a negative experience $(0.7 \%)$ and the remainder $(11 \%)$ fell in the neutral category (neither negative nor positive). Few respondents (16) among those who had participated in more than one cultural event (130) chose two different options to describe two different types of experiences.

\section{Reported benefits of participation}

Individual well-being benefits, such as relaxation, recreation and taking a break from things (psychological detachment), were frequently reported, whereas workplace community benefits such as familiarization, open communication, good atmosphere and cooperation were reported to some extent and insight-related benefits (new ideas and reflection on professional identity) were not commonly reported (Tab. 2).

\section{Spontaneous description of cultural experience}

The open-ended question 'Describe your experience of the cultural event in your own words' evoked more personal and detailed comments than the multiple-choice questions. The open responses $(\mathrm{N}=288)$ were classified into three main categories: positive $(\mathrm{N}=141)$, negative $(\mathrm{N}=44)$ and evaluative attitudes $(\mathrm{N}=91)$. Furthermore, there were 12 neutral comments not related to any of these. These categories demonstrate emotional experiences expressed in the discourses of free comments. 
Table 2 Benefits obtained by participants

\begin{tabular}{lccc}
\hline Type of benefit & Mean (Scale I-5) & Range & SD \\
\hline Detachment & 4.2 & $2-5$ & 0.728 \\
\hline Relaxation & 4.4 & $2-5$ & 0.617 \\
\hline Recreation & 4.4 & $2-5$ & 0.640 \\
\hline New ideas & 2.8 & $1-5$ & 0.975 \\
\hline Reflection & 2.8 & $1-5$ & 1.039 \\
\hline Familiarization & 3.6 & $1-5$ & 1.003 \\
\hline Communication & 3.6 & $1-5$ & 1.004 \\
\hline Atmosphere & 3.6 & $1-5$ & 0.991 \\
\hline Cooperation & 3.4 & $1-5$ & 0.987
\end{tabular}

\section{Positive attitude}

An active positive attitude toward cultural events in the workplace was reported by half of the respondents. All these employees described cultural activities with many positive words. The most frequently used words were 'pleasant', 'refreshing', inspiring', 'interesting', 'important' and 'relaxing'. Respondents provided comments, which were strongly directed to well-being experiences. In the majority of the responses, the meaning of workmates and workplace community-being invited and being together-became evident. 'Cohesion' or 'the feeling of belonging together' was frequently mentioned. The positive interaction at cultural events was also reflected in the workplace atmosphere and communication: 'At work, it is easier to approach a person that has already become a little familiar'.

Despite meeting workmates in leisure-time, none of the participants reported any confusion between work and leisure. Instead, detachment from everyday work and routines was reported. The rich variation in the supply of cultural events was appreciated. The significance of initiative from employer or workmates was often mentioned by those who had not cultural activities of their own. Some respondents were grateful to have found new meaningful hobbies by being introduced to cultural events by their employer. Many newcomers expressed their satisfaction at the easy way of getting in touch with cultural events and having tasted something new by being encouraged by their workplace. Some respondents expressed their wish for more options for participation-more events and more tickets available. Positive workplace atmosphere effects and positive interest were also expressed by some of those who had not yet had the chance to participate.

The positive responses reflected three important values: first, personal meaning and well-being experiences: How they feel about participating in cultural activities (pleasure, relaxation, stimulation, recreation, new ideas, personal development and other good qualities of well-being); second, cohesion, atmosphere and shared experiences with workmates: How important it is to spend time outside the workplace and build on shared meaningful experiences; and third, appreciation and gratitude to their employer for organizing and making these events possible. When looking at these three values 
described by respondents, it is possible to identify their commitment to work and the importance of well-being.

These three values were often intertwined in the responses so that their classification into sub-categories is not exclusive. Each response was classified according to most prominent theme, ignoring other parallel themes. This means that those classified as predominantly related to personal well-being may often include other values, too. Five positive responses were so broad or encompassing that they were not classified into sub-categories presented below. Seven examples of free comments representing each sub-category are given:

\section{Personal meaning and well-being $(N=69)$}

'They were pleasant and variable events. I would not have had the initiative to go there alone'.

'Refreshing experiences, food for the soul, a counterbalance for everyday routines'

'Relaxing and giving new, inspiring ideas'.

'Refreshing, a free exchange of ideas'.

'New views into life challenges and work. Ideas for learning methods...'.

'A refreshing effect for work. Increased motivation and initiation. This affects also social participation, inspiration, new ideas and activities outside work. It is not that difficult once you get started!'.

'Work-place cultural activity helps to detach from work routines and everyday problems at work. The cultural activity provided by my employer activates me to participate'.

'It is good to have different kinds of cultural happenings provided by my employer. I would not have the initiative to buy a ticket to the theater, by myself, for example. This is easy for me, having it organized by my employer. Now it is possible for me to get familiar with new fields of culture that I would not find by myself. Participation is always refreshing'.

\section{Cohesion and atmosphere $(\mathbf{N}=34)$}

'You get acquainted with workmates and have more team spirit at the work-place'.

'A pleasant way of spending time with my own workmates! At the same time, you see and come to know nursing personnel from other units'.

'The events are delightful and the workmates are relaxed there, so we come to discuss other things than work affairs'.

'This matters for coping with the workload. Role change and getting acquainted with workmates'.

'Work-place cultural activities unite personnel, and lower the threshold to participate'.

'Creates feeling of belonging together. The workmates' enthusiastic stories about a good theater play brighten up the day for us others, too. The shared joy is great! I appreciate this even if I cannot go with them. Maybe one day I will have time to go'.

'I am very glad that my employer organizes recreational cultural activity. Inspiring experiences give energy for work and I feel that this is a message to employees that our wellbeing is taken care of by them with concern and responsibility. The responsibility for one's own wellbeing is easier to carry when getting support from the employer, too'. 


\section{Appreciation and gratitude $(\mathrm{N}=38)$}

'Excellent act by my employer, because this clearly gives mental stimulation, and otherwise these events would have been missed. Nice to meet workmates and talk with people. Very important extra support for coping with the workload'.

'Really nice of the employer to make it possible to participate cultural events with workmates. Our positive work-place atmosphere in increased. We get to know even more distant workmates. The supply (of cultural events) has been interesting and rich in variety. Something for everybody'.

'I consider the cultural supply from the work-place as a valuable extra benefit and a proof of the willingness of our employer to invest in our coping with workload'.

'I appreciate the cultural leisure activity organized by our employer. This is a chance for us, not forced on us. Sufficiently varied cultural supply, to my mind'.

'I am grateful for the cultural program and I have been reasonably well able to participate, though often with a late reservation released by cancellation, because the demand exceeds the supply'.

'Very good, otherwise one would skip these occasions, either because the art-form, or the price of ticket. This demonstrates the caring attitude of the employer. Much better than coffee and cake'.

'I am very grateful for the opportunity to participate. This is a privilege when you have a low-salary. Without this you might not have the chance to go out. After every event I have felt excited and empowered'.

\section{Negative attitude $(\mathrm{N}=44)$}

The category of negative attitudes showed a heterogeneity of ideas. Active rejection and passive rejection, as well as giving up the idea were included in this category. The rejecting attitudes were expressed by those who had enough with their individual cultural activities and those who found the workplace cultural program not interesting or not suitable for them. Lack of time due to work-shifts, family and studies were reported in free comments to explain the rejection. The free comments reflected the same obstacles as the multiplechoice responses (see Reasons for non-participation), but they also revealed some feelings of unequal chances to access the cultural events for those working in shifts (see Evaluative attitudes). Some respondents rejected the cultural events, because they did not have the chance to participate together with workmates as they we working in shifts-this also evoked feelings of unfairness.

Most prominently expressed themes, however, in the rejecting attitude category were the priority of individual leisure activities and the desire to keep work and free-time separate. A few respondents reported a very sharp line between workmates and private social networks. Some employees did not like to meet work colleagues after work, or they were already heavily involved in their own activities. Unlike those who participated, some of the non-participants feared of being not able to leave the work behind. The grand consumers of culture, on their part, did not have time nor interest for the workplace supply of cultural events.

Furthermore, there were occasional responses without a clear trend. Some of the responses expressed frustration with working conditions, leaving aside the discourse of 
cultural program or providing it with negative connotations. Two respondents were so exhausted by their workload that they found it difficult to participate. One respondent felt insulted by the cultural program, reporting it to be in contrast with the increasing work demands and uncontrollable working hours. One declared workplace cultural program to be a vanity (see quotations below). Two of the respondents considered the cultural program to be targeted more at older employees, and one reported them to be more suitable for younger colleagues, while others were simply not able to get to the events. Seven examples of negative comments are given below:

'I have enough with my own hobbies, so I don't need this via my workplace'.

'Cultural activities are necessary, but I am a grand consumer of culture so the workplace cultural program is not so relevant to me'.

'Recently, there have been good recreational activities available, but I had not had time for them because of my own hobbies'.

'I don't need any cultural activities from my workplace, unless I can participate during working hours.'

'I do not visit cultural events organized by workmates nor work-place, because I pursue my leisure activities only and exclusively with my friends and family. Workmates are only workmates, though they are fine, I still would not spend my leisure time with others than very few chosen ones'.

'Work-place cultural program is a vanity. Is it not enough, that in this country, you must work with low salary and spend most of the time with workmates? Cultural activities belong to leisure, and everyone can use them as they will. Hospital work does not become more creative by cultural happenings'.

'It is too hard to look for the information'

\section{Evaluative attitudes $(\mathrm{N}=91)$}

Evaluative ideas were focused on both outer and inner realities, sharing an interest in cultural events. Most evaluative responses reflected the outer problems of accessibility, ticket and information supply, but some responses reflected inner, or more personal, obstacles. After those with outer, organizational comments, the second biggest group was those who were still thinking about participation, expressing an inner dialogue of speculating their interests and chances concerning participation. Quite many were enthusiast or concretely planning to participate. Some of the responses were controversial in themselves, and the respondents themselves identified the ambivalence expressing an inner, reflective discourse. Asking about cultural activity seems to evoke a rich variety of ideas and emotions related to personal development. The most personal themes are not quoted here to protect privacy.

Even many of those who did not participate had evaluative comments and ideas for developing the program. Some of them were more general, positive remarks about the enriching effects of cultural activity for life and for coping with work, not related to personal experience. Many respondents who suggested improvements paid attention to the problems in obtaining tickets or information about events. Many employees mentioned the reason for this problem as being not on a computer at the right time to reserve tickets. The frustration with missing the tickets aroused a discourse related to fairness. Reflections of being privileged, and being exposed to envy, were occasionally expressed in the evaluative free comments. 
Quite a few suggested concrete improvements, such as a more equal distribution of tickets, to at least guarantee access for all new-comers. Two respondents commented that they would have preferred sports and outdoors activities. Ten respondents would rather have had cultural vouchers to have their own individual cultural activities supported, or to share the experiences with their family and friends, to guarantee availability of tickets or just have more free choice in terms of timing and forms of culture. One of them, however, concluded that the cultural events organized by employer are the 'surest' way to get involved with cultural activities.

Seven examples are given below:

'The information (about cultural events) is published on the Intranet. By the time you find out the information, you find that all the tickets are booked already'.

'As I work shifts, I miss the events, as the tickets are already allocated by the time I have time to enter Intranet. In the bus, with the employees from our organization, you can hear it on the grapevine'.

'I would participate, but often the night-shifts and timing of cultural events are overlapping'.

'The quick ones overcome the slow ones. Just a few have access to cultural events. I would prefer cultural vouchers to give a choice to everyone. Our department has organized good occasions, but with low access'.

'The initial enthusiasm and enrollment is not always enough for participation. There will be cancellations. The reason is some inconceivable bothering on the level of mind/ emotion'.

'My readiness for participation would be higher if I was not so fed up with the work at the end of the day. I have participated within the limits of my health. Sometimes the enrollment system has reduced the pleasure of participation'.

'I hope that the program will be continued. It helps to cope with the daily work routines, in particular, as the working life is getting harder and the demands are increasing...'

The cultural activities in the workplace connect together two important aspects of wellbeing: 'job-specific' and 'context-free' well-being. This means that participation in cultural events together with work colleagues can support both aspects of well-being. By involving work colleagues, there is a workplace context, and yet the events are not carried out at the workplace. This study shows that a positive attitude toward cultural events experienced together with work colleagues gives rise to well-being discourse. This in turn may enhance job satisfaction and improve general well-being, thereby having an effect on increased work involvement (Warr, 1999, p. 392-407).

The workplace context contaminated attitudes to cultural activity, and vice versa. Experience of psychosocial adversities at work (e.g. high demands, low reward, unfairness expressed in four responses) were clearly associated with critical and rejecting attitude toward the cultural program. The critical respondents mostly disregarded the discourse about cultural events, as they focused on their work experiences and carried further the organizational discourse onto a specific solution-oriented level. Opinions on reform, leadership, feedback and reward were presented. When the basic work conditions are experienced clearly unsatisfactory, there is no room for nor interest in positive interventions such as cultural activities. 
The positive attitude toward cultural program was related to positive evaluations about employer, particularly among those who participated in the cultural events and reported positive experiences. Gratitude and appreciation for employer were the most common themes in the discourse with work-context among participants. Non-participants, who expressed evaluative attitudes and positive interest-or plans to participate later-reported some positive comments related to their employer, but fewer than participants. According to discourse analysis, it seems that a positive attitude to the employer is not necessary for participation, and obtaining the benefits, but a negative attitude to the employer, or a negative experience of working-conditions hampers, or even prevents, participation by creating a barrier of negative expectations, devaluation and withdrawal.

Exhaustion or stress, if not too severe, seems not to be an obstacle, but rather a motive to participate with aims of well-being. Some respondents who reported tiredness seemed to need more work-mate encouragement and easier biking system for tickets, whereas others praised the well-organized, ready-made program for easy participation. Many commented that without the cultural workplace program, they would not have entered such cultural events and they expressed their satisfaction for finding these new experiences.

\section{Discussion}

\section{Main benefits of cultural events}

The experience of cultural events was predominantly positive and the major gains reported were relaxation and recreation in the quantitative analysis. These gains were in most cases the same as the aims reported by participants. Our hypothesis was supported by quantitative analysis in terms of psychological detachment from strain, relaxation, recreations, familiarization with workmates, increased communication, better atmosphere and cooperation, but not when it comes to new ideas or reflection on professional identity. The mean subjective creative effects were lower than the mean subjective wellbeing and interaction effects. Despite the employer-provided context, the cultural activity did not activate work-related thoughts and ideas but instead, it served as a means of psychological detachment, relaxation and recreation. However, some workplace-related positive experiences were reported, which may be mediated by the high community participation, insofar as the employees participated with several work colleagues rather than alone or in couples (Tab. 1). Instead, descriptive data illuminated experiences of increased inspiration and idea exchange between workmates that was transferred into workplace and reflected in a better working climate and more fluent social interactions in the workplace.

\section{Cultural events and recovery}

Earlier studies show that the consumption of culture is associated with different mechanisms of occupational well-being rather than creative activity; the former relates to work engagement, through psychological detachment and relaxation, whereas the latter is more related to a creative working mode, through stimulation and the transfer of a 
flexible, creative way of thinking from leisure to work (Tuisku et al., 2011). Psychological detachment ('taking time out') and relaxation belong to the four major psychological mechanisms helping recovery from stress: They can be seen as personal strategies through which individuals try to restore their energy resources and maintain well-being despite stressful situations (Sonnentag \& Fritz, 2007). Recovery processes are mediating mechanisms between work characteristics and occupational well-being. Psychological detachment is an essential protector from exhaustion and health impairment in highstress work and is also a prerequisite or antecedent for relaxation (Kinnunen et al., 2011).

\section{Obstacles to participation}

In this study, a lack of information and a shortage of time seemed to be the biggest obstacles to participation, the former being manageable and the latter possible to consider in work-shift planning. There were several items available to choose from, which gave two typical explanations for the reported lack of time: More often work shifts than family reasons. The lower participation among those with shift work is primarily explained by overlapping schedules between work shifts and evening-time cultural events. Furthermore, those who work outside official hours may miss some information about workplace meetings and they are not the first ones to reach the tickets. Temporary employment was also associated with lower participation. Looser, and less established social networks in the workplace community may offer an explanation here.

For more extended participation, equal availability and optimal workplace benefits, the information and invitation practices could be rather improved by line managers responsible for practical daily communication and work-shift planning rather than through the information on the website. Managers and employees should be encouraged to invite in particular those colleagues who are new or not so familiar with the program. Collective participation would increase their social networks and sense of belonging. Secondly, the regularity and continuity of the employer-provided cultural activities over a longer period-as in this example-made them available to a larger number of personnel. Nevertheless, there will always be a proportion of personnel who are not involved in these kinds of activities because they have meaningful reasons for not to participate related to other priorities, that is family and lack of interest, also revealing that they would not be the optimal target group when it comes to the benefits of these kinds of activities.

\section{Consumers of culture}

The results of this research are in line with Finnish people's attitude toward cultural events in general (Center of Statistics, 2013; Finnish Cultural Foundation, 2013). Finns are ready to participate in some cultural activities, if they are collectively appreciated (with family, work colleagues or other parts of society). Many workplaces have a tradition of going to the theater or a concert together once a year. Besides, the tax-free vouchers are used by many employees for sports or art activities.

The regular cultural activity provided by employer supports context-free wellbeing, and naturally, it is intended to be beneficial, but this study shows that there is an 
additional benefit from collective participation within the workplace community. Results show that people who are highly active in cultural events are also very happy and satisfied to share these experiences with work colleagues. These results also support the view that job-specific well-being can be stronger when people have shared experiences of cultural events. Experience in this vital sense is defined by those situations and episodes that we spontaneously refer to as being 'real experiences', those things of which we say in recalling them, 'That was an experience'. (Dewey, 1980, p. 204-208).

The consumption of culture in workplaces and leisure activities is also a gender question. In this study, mostly women were active in cultural events. The difference between male and female participation was significant in addition to the fact that most of the hospital personnel are women. The overall tendency of middle-aged, educated women to consume culture among the Finnish population (Finnish Cultural Foundation, 2013) is consistent with the findings of this study. The 'grand-consumers' of culture represent $6 \%$ of the population. Qualitative responses to this study revealed that the 'grand-consumers' had their own established ways of consuming culture that they preferred to the cultural events offered by employer. Thus, the cultural program rather reached the new-comers or occasional consumers of culture than those who had their established cultural leisure activities.

Indeed, the most often reported motives for participation were not the enjoyment of the arts in general, or an interest in a specific form of art, but recreation and relaxation, elements of recovery and well-being. The cultural activity seemed to reach those employees who most needed it and who would not necessarily have engaged in those cultural activities without the initiative and sponsorship of the employer. The most frequently visited cultural event in this study was the theater, but all the events were fully booked; thus, the amount of participation was not determined by the choices of the participants, but rather by tickets and events available and offered by the employer. In the Finnish population, the most popular cultural leisure activities are the cinema and theatre (Center of Statistics, 2013).

\section{Cultural activities and the concept of social capital}

Shared cultural experiences and exchange of ideas around them serve as a platform for familiarization, openness, trust and reciprocal communication. The construction of social networks in the workplace can be limited by time pressure at work, turnover of personnel, shift-work and barriers created by hierarchy, organizational units, different professional roles and paradigms. Collective cultural experiences among employees outside the definitive structures of the workplace offer extraordinary chances to overcome these barriers. Knowing workmates and superiors a little more, and seeing them behind their tasks, will make it easier to approach them in work matters, to understand their way of communication and to share professional interest and goals with them. The forms of social connectivity, shared values of reciprocity and trust are the components of social capital, which is associated with better subjective health of employees in the workplace (Oksanen, 2010, p. 84). Indeed, social capital has been suggested to lie behind the wellbeing effects of collective cultural activity (Hyyppä, 2014, p. 22).

Compared with cultural vouchers, this kind of workplace cultural program seems to have more collective benefits in relation to social capital of in the workplace; increased 
social connections and communication among workmates and across organizational units, increased team spirit and exchange of new ideas and the experienced support from employer were reflected in the free comments. Furthermore, there was no risk of misuse with this type of cultural supply, and no waste of tickets as all the events were fully booked. In addition, invitations from the employer or workmates made the cultural experiences easily accessible for those employees who would not have tried them on their own initiative. Instead, cultural vouchers are used to sponsor established individual leisure activities, which are also valuable for well-being, but do not necessarily offer new experiences nor collective experiences with work-mates.

\section{Applicability of workplace cultural program}

What this study has shown is that easy access, effective information channels and equal availability are essential to obtain the optimal benefits from workplace cultural program. A variety of options is also important to lower the threshold for access and to offer new experiences. Basic work safety and occupational health issues should first be adequately addressed, before it is possible to build up social capital by cultural activities. Cultural programs need careful planning and monitoring to be responsive and adapted to organizational needs. The timing of cultural events outside working hours is an adequate solution to guarantee voluntary basis of participation and to maintain productivity. Besides, cultural events with workmates outside the workplace environment and routines of working hours enriched the social networks and positive interaction, which, in turn, was reflected in the working climate according to the descriptive data.

Previous studies (Theorell at al., 2009, 2013) also address the importance of the broad coverage of workplace cultural interventions. By encompassing more cultural activities, available to all personnel, experiences of envy and unfairness can be avoided. In our study, it is remarkable that the third part $(33 \%)$ of those who did not participate in cultural program reported the lack of information to be reason. The shift-workers, who seemed to have lower access to information and tickets, and sometimes looser social networks at workplace, should be specially taken into account when planning the cultural program in order to guarantee their equal chances of personal well-being and functional social networks in the workplace. According to Theorell et al. (2013), the health effects of cultural activities in the workplace can be mediated by the strengthening of cohesiveness and an improved psychosocial work environment or by the direct personal effects of cultural activities.

Earlier studies have shown the linear dose-response connection between frequency of cultural activity and mental well-being (Theorell et al., 2013; Tuisku et al., 2011). In this study, the cultural events were offered monthly. This is lower frequency than in some other studies (Bygren et al., 2009; Theorell et al., 2009), but higher than the lowest effective workplace cultural interventions (Theorell et al., 2013). Higher frequency would become more expensive for the organization, but the availability and choice of timing would increase. Very early planning and information of the cultural program, together with flexible work-shift planning, would increase the equality and chances to participate without extra costs. Availability to all employees is important, but also free choice is essential, because non-motivated participation could have adverse effects. A rich variety of cultural events was appreciated in this study, which may lower the threshold for new participants. 


\section{Limitations of the study}

The response rate was relatively low $(35 \%)$, questioning the general applicability of results and lowering the power of analysis and conclusions. The response rate, however, is comparable to the standard response rate $(36 \%)$ in organizational studies (Kinnunen et al., 2011) and characteristics of study participants were comparable to general personnel structure of the hospital. Further limitation is a lack of time on the part of respondents during working hours, which probably leads to few descriptive responses to open questions. More employees could have participated in cultural events, if the availability of tickets to all newcomers could have been guaranteed. An implementation study of workplace health promotion has concluded that there is a need to observe the relationship between logics related both to the project and to the organization (Bjornstad \& Steen-Johnsen, 2012).

In this study, the cultural program was carried out in terms of the organization, not as an experimental, randomized study setting. This study is thus not an intervention study with a comparison group, but it is a naturalistic, partially qualitative approach to explore the implementation and categorized experiences of cultural program. The richness of the study (descriptive qualitative data obtained by 288 free comments) is also the part that is most context-related, and thus most difficult to generalize. The naturalistic setting, as not standardized, reduces its generalizability to other organizations. The generalizability is limited to public sector hospitals with similar personnel composition and similar recreational program. Due to cross-sectional and retrospective character of the study, the follow-up data are missing. The qualitative data, about the need for equal availability in particular, initiated major improvements to the cultural program. The effects of these improvements, unfortunately, are not available and there is a need to follow the activities over longer time to be able to build up evidence.

\section{Conclusion}

The positive effects of workplace cultural interventions have been established, but a little is known about coverage and implementation of these programs-do they reach the right targets?

In this study, a workplace cultural program with monthly cultural events outside working hours missed some of the targets. The timing of relatively infrequent cultural events should be taken into account in planning work-shifts to guarantee equal access for all together with workmates. The intervention did not reach all who would have been able to benefit, because the need exceeded the supply, and work-shifts hampered participation. But, on the contrary, those who participated were the correct targets. The intervention succeeded in inviting employees with well-being motives and new consumers of culture, instead of attracting established grand consumers who preferred pursuing their private activities.

The aims and motives of the participants were met by the cultural events: They experienced recreation, relaxation and psychological detachment from strain. They also reported increased social interaction, exchange of ideas, team spirit, appreciation of their employer and familiarization with workmates across the units leading to benefits at workplace. Cultural events outside workplace and outside working hours are 
meaningful for voluntary and optimally motivated participation, and for building social networks and positive interaction. Before cultural workplace program can reach its maximum benefits, the basic work safety issues should be adequately managed. The workplace cultural program described here is generalizable to other public hospitals. Compared with cultural vouchers, this kind of program encourages more collective workplace participation and minimizes the risk of waste, but it narrows the free, individual choice of consumers.

\section{References}

Bittman, B., K.T. Bruhn, C. Stevens, J. Westengard, and P.O Umbach (2003) 'Recreational music-making: a cost-effective group interdisciplinary strategy for reducing burnout and improving mood states in long-term care workers', Advances in Mind-Body Medicine 19 (3-4): 4-15.

Bjornstad, T.C. and K. Steen-Johnsen (2012) 'Beyond planning: The implementation of a Worksite Health Promotional Scheme', Nordic Journal of working life studies 2(2): 51-70.

Bygren, L.O., G. Weissglas, B.M. Wikström, B.B. Konlaan, A. Grjibovski, A.B. Karlsson, S.O. Andersson and M. Sjöström (2009) 'Cultural participation and health: A randomized controlled trial among medical care staff', Psychosomatic Medicine 71(4): 469-73.

Center of Statistics (2013) Ajankäyttötutkimus subjektiivisen hyvinvoinnin tietolähteenä (Study of leisure habits as a source of information about subjective well-being). http:// www.stat.fi/artikkelit/2013/art_2013-06-03_007.html (last accessed 8 January 2014)

Dewey, J. (1980) Art as Experience. New York: Putnam Publishing Group, pp. 204-8.

Finnish Cultural Foundation (2013) Suomalaisten näkemykset kulttuurista 2013 (Views of the Finns on the culture 2013). http://skr.fi/sites/default/files/Suomalaisten_n\%C3\%A4kemykset_kulttuurista_2013.pdf(last accessed 8 January 2014)

Gee, J.P. (2005) An introduction to discourse analysis: Theory and method. New York and London: Routledge.

Hyyppä, M.T. (2014) Kulttuuri pidentää ikää (Culture prolongs life) Duodecim, Helsinki, pp. 22 and $115-6$.

Iwasaki,Y., R.C. Mannell, B.J. Smale, B.J. and J. Butcher (2005) 'Contributions of leisure participation in predicting stress coping and health among police and emergency response services workers', Journal of Health and Psychology 10(1): 79-99.

Jones, M., R. Kimberlee, T. Deave and S. Evans (2013) 'The role of community centre-based arts, leisure and social activities in promoting adult well-being and healthy lifestyles', International Journal of Environmental Research and Public Health 10(5): 1948-62.

Kelaher, M., D. Dunt, N. Berman, S. Curry, L. Joubert and V. Johnson (2014) 'Evaluating the health impacts of participation in Australian community arts groups', Health Promotion International 29 (3): 392-402.

Kinnunen, U., T. Feldt, M. Siltaloppi and S. Sonnentag (2011) 'Job demands-resources model in the contextof recovery: Testing recovery experiences as mediators', European Journal of Work and Organizational Psychology 20(6): 805-32.

National news (2013) 'Arvoseteleissä liikkuvat isot rahat -setelit virtaavat vääriin käsiin' ('A lot of money invested in Vouchers -part of them are not properly used') http://yle. fi/uutiset/arvoseteleissa_liikkuvat_isot_rahat_-_setelit_virtaavat_vaariin_kasiin/6442091 (last accessed 27 January 2015)

Moreno-Jiménez, B., A. Rodríguez-Muñoz, A.I. Sanz-Vergel and E. Garrosa (2012) 'Elucidating the role of recovery experiences in the job demands-resources model', Spanish Journal of Psychology 15(2): 659-69. 
Oksanen, T. (2010) Workplace Social Capital and Employee Health. Turku: Doctoral thesis. University of Turku, p. 84. http://urn.fi/URN:ISBN:978-951-29-4083-7.

Sonnentag, S, and C. Fritz (2007) 'The Recovery Experience questionnaire: Development and validation of a measure for assessing recuperation and unwinding from work', Journal of Occupational Health Psychology 12: 204-21.

Theorell, T., M. Hartzell and S. Näslund (2009) Brief report. A note on designing evaluations of health of cultural activities at work. Arts Health 1: 89-92

Theorell, T., W. Osika, C. Leineweber, L. Magnusson Hanson, E. Bojner Horwitz and H. Westerlund (2013) Is cultural activity at work related to mental health in employees? International Archives of Occupational and Environmental Health 86(3): 281-8.

Tuisku, K., Pulkki-Råback, L., Ahola, K., Hakanen, J., and Virtanen, M. (2011) Cultural leisure activities and well-being at work: A study among health-care professionals. Journal of Applied Arts \& Health 2: 273-287.

Warr, P. (1999) 'Well-Being and the Workplace'. In D. Kahneman, E. Diener and N. Schwarz (eds), Well-Being: The Foundations of Hedonic Psychology. New York: Sage, pp. 392-407.

Willig, C. (2008) Introducing qualitative research in psychology: Adventures in theory and method. New York: McGraw Hill and Open University. 